\title{
A Study on the Metaphorical Fox Image of Cross Culture between China and Japan
}

\author{
Shuqing $\mathrm{He}$ \\ College of Humanities \\ Zhejiang University \\ Hangzhou, China 310000
}

\begin{abstract}
More and more modern literary works begin to show a fox image, the fox was given a lot of mysterious colors. In these works the public was not only attracted by fox itself, but also attracted by the human nature that the content reflects. However, whether in China or Japan, the fox image still has some differences among the sameness. This paper makes a brief comparison of the mainstream fox image in Chinese and Japanese culture, analyzes the humanistic manifestation of the fox image in Chinese and Japanese culture and the cultural differences between China and Japan behind the connotation of human nature.
\end{abstract}

Keywords-fox image; human connotation; Chinese-Japanese culture; metaphor; cross-culture

\section{INTRODUCTION}

With the mix and blend of literature in the world, fox image has been presented in many modern works. Modern literature and even film and television works consider fox this image as the popular trend. And since ancient times the stories of fox have spread in various places, the European "Aesop's Fables", China's "Guangyi Ji" and Japan's Inari and so on are all the legends about fox. So in the long history of cultural what gives fox such special yet attractive charm?

\section{The TeXtual CRiticism OF Fox IMAGE}

China's fox culture is more complex, roughly takes Tang Dynasty as the division. After Tang Dynasty fox culture was recorded with heavy color in the history because of human breakthrough, its influence last until today.

Legend or story can be deeply and widely spread with unique charm, first of all is because its own artistic value. Hegel said: "When art comes to maturity period, it must be presented with the image of people according to the necessary law." [1]The reason why fox image is able to attract the public is precisely because of its rich humanized expression.

China's earliest fox faith appeared in the "Shan Hai Jing", "In the north of Qingqiu country, there are foxes with four feet and nine tails. Also there is a saying they lived in the north of Chaoyang." [2] (" Shan Hai Jing. Hai Wai Dong Jing ") and Guo $\mathrm{Pu}$ wrote in his "Shanhaijing Tuzan" that: "There is a beast in Qingqiu, it is a fox with nine tails. Sometimes you can see it on the road; it will hold a book in its mouth when it is out. It will use the book as auspicious words and use it to make spiritual magic figures." [3] Fox was given auspicious meaning here and at the same time it was divinized. To the Han Dynasty, when the god theory was very popular, people were affected by the idea of "old things become immortal", fox was given an evil spirit image and gradually being demonized. And after the Tang Dynasty, fox was written in a lot of mythical novels. The audience of this kind of story moved to the common people, so that fox began to intervene in people's secular life, changed from "fox eat people" into "fox change into people", fox image began to show the trend of human content. Until the Ming and Qing Dynasties, Yuan Mei's "Zi Bu Yu", Ji Yun's "Yuewei Caotang Notes" and Pu Songling's "Liao Zhai Zhi Yi" (Strange Stories from a Chinese Studio) and so make the fox image increasingly rich, fox image developed into mature and reach the peak.

In Japan the division point of fox is also the Sui and Tang Dynasties. Before Tang Dynasty, fox image often exist as "good". Fox as a religious belief - Inari, is the messenger who brings the harvest. In the folklore, it often appeared as the fox wife. Since Nara period (AD 710-794), Japan sent emissaries to Tang, Jianzhen visited Japan and brought Chinese culture into Japan, Japan's fox culture was also affected by China and changed.

Fox image was born with the aboriginal faith, after the influence of Japanese native religion - Shinto, put aside the animality of fox itself and transit into the fairy fox image. In Yayoi period (300 BC - $250 \mathrm{AD}$ ) the Inari civilization began to develop, because fox eats the rat in rice field so gradually it becomes a symbol of rice field guardian. Therefore the fox was apotheosized into the messenger of Inari. With the development of history, the image of the Japanese fox image gradually humanized, the biggest expression is the image of fox wife. Fox turned into beauty and married with man, and then became a mother, among which contained human feelings and the expression of Japanese culture. Take "Japan Ryouiki" as the representative, the book tells the story about the fox wife in Mei Nong state.

After "Ling Gui Zhi" introduced into Japan in Tang Dynasty, it spread widely in the folk, and the fox was also closer to the folk life. What we can see is that before the Tang Dynasty and Japanese Nara period, most of the literary works or folklore is from the viewpoint of the third part, telling the fox story with objective statement. When it involves "people", it just slides over without any description based on fox itself 
which embodied the ideas. But after Tang Dynasty, the description of the fox gets gradually rich, and closer to the secular. The plot of fox story became vivid and full of twists and turns, whether it is through the whole story to alert the world, or through the fox to tell human's thought in reality, they all clearly reflected human nature connotation of fox image.

\section{THE CONTRASTIVE ANALYSIS OF MAINSTREAM FOX IMAGE IN CHINA AND JAPAN}

Under the humanized expression, the content of fox story became plentiful and with connotation. So through the plot expression and the contrast of story ends, you can find the mainstream fox image in China and Japan's legend is different.

Chinese fox usually changes into beautiful women to tempt man, and after the man is aware that she is a fox, he will run away from the fox or the Taoist priest will use magic to drive the fox. Japanese fox turns into a fem to marry with man and gives birth to children. After she is found her fox identity, she will leave by herself and mostly the final outcomes are the man still loves the fox.

In Chinese fox story, the fox turned into beauty and seduce men is to make themselves strong by using men's blood and energy. This gave the woman's image a layer of "siren" feeling. In Volume twenty-one of the "Yuewei Caotang Notes", it described the fox as a very beautiful woman:

Her voice is charming, and she has been to the bed, touching his face with her hand, her fingers are slim like green onion in the spring and smooth like jade, she has fragrance of rouge powder and attracts people very much. The man knows she has bad intention but he is tempted by her, so he wants to sleep with her and sees what will happen. So he sleeps with her and loves her with passion. Until the happy moment, he suddenly feels a sucking power from her belly and then he is perturbed in mind and down to unconscious. [4]

Fox stories mostly start around the man and centered by the man, highlight the image of Chinese men. Chinese fox women do not have children, and most of the ends the fox is found by the man and then is driven or killed. This kind of story fully embodies the fox's demon, much tempting for men as harmful for them. This is to warn the man of beauty who is the source of trouble and not clinging to the beauty.

In Volume fourth hundred and fifty of "Taiping Guangii", the chapter of "Xu An" of Fox Four has written: "An was angry and attack with sword, three young men died. The next day when he returned there and see the young men he killed last night, they were all old foxes." [5] The article of "Ru Shi Wo Wen" in "Yuewei Caotang Notes" also mentioned that when the men find the women who sleep with him is a fox, he got very angry and want to kill her. "Xiao Lian was very angry and held her cheek, willing to tie and beat her. During the fight, his roommate heard and come to help him. But suddenly the fox get away and jump out of the window and run away." [6] This shows that in China when they found the one close to them is fox, they normally fear and hatred for them, and finally all put it down to the fox women get close to a man in order to hurt him. China's attitude toward fox is very different from Japanese men who miss and want to get there fox wife back.

The most famous in Japan fox legend is fox wife image; it was spread widely, and also was the representative of Japanese local fox culture.

In Nara era, "Japanese Ryouiki" recorded the man found his wife was a fox, but still loved her and could not forget her, he even named his child Hu Zhi (Fox Just):

The husband saw her face, sang as ... so that he named his child as $\mathrm{Hu} \mathrm{Zhi}$. The child is people but has strong force and runs very fast like birds. In the Sannai State, Hu Zhi is the main character. [7]

In Japanese fox wife legends; there are more descriptions about the fox wife. In Japan it often present as fax wife image in order to highlight the goodness of fox and fox wife's greatness of motherhood. In legend Japan's famous Onmyouji Abe No Seimei's mother was white fox, but in fact his mother was a woman with low status. Through this rumor can be seen that Seimei through fox to improve his social status, that is, the existence of fox mother image has provide positive influence for the man side. For the same reason, the fox wife in "Ge Ye" left after her fox identity was found and left the song, which roughly means "If you still love me, come to find me." Fox wife was snoopy, and the man also did not drive or even kill the fox wife. Here the fox wife is the good image and have children with the man. It is sympathetic to the mother's image when she shows her bones and has to leave the child. It can be said the description of the man image is also to highlight the fox wife, which rendered the sadness feelings of the wife. So the legend of the Japanese fox wife to a certain extent is the prominent of fox image.

But from the endings, the fox image in China and Japan are mostly tragedy, and at this point it seems to maintain consistency. Japan's "Xintai's Wife" wrote: After fox wife was found by the man or child she was ashamed, and then escaped. Similarly, the story of the Chinese fox is also with tragic fate, either fox is dead or the whole family is dead. In "You Ming Record", Chunyu Jin and fox woman fell in love at first sight, but in the last the three people including mother and son all dead. In "Guang Yi Ji", there is a fox married to Helan Jingming, and in order to integrate into the family, she has to steal other's mirror, and is finally beaten to death. For the endings, both the two countries all formed the situation of "lovers can not be together".

However during the study, the exceptions all appeared in both the two countries' fox images.

Pu Songling's "Liao Zhai Zhi Yi" (Strange Stories from a Chinese Studio) in the Qing Dynasty gave the fox great human content, and the idea of free marriage was through the whole book. Fox's illusion not only did not bring disaster, but helped the people. Although some of the stories can not take off the tragic ending, but in the most famous fox-human marriage of "Liao Zhai Zhi Yi", the fox was removed from the factor to tempt people, each fox woman in the book has a distinctive personality, and the happiness close to life is expressed. This is closer to Japan's good fox. 
Japanese song "Sha Sheng Shi" describes the story of Tomamo-no-mae. Tomamo-no-mae was changed by the nine tailed fox and favored by Emperor Toba. Like King Zhou of Shang, Tomamo-no-mae tempted the Emperor and made him to ignore the government and even had a strange disease. At last she was killed by Shinzo Abe and turned into Sha Sheng Shi. This story violates the Japanese mainstream fox wife image, Tomamo-no-mae attracted the emperor in order to use his energy and blood to power herself and was finally killed by the Onmyoji, which is closer to China's mainstream fox story.

Why is there such image outside the mainstream? Although the predecessors did not explain this, but after careful study we can still find out some of the reasons.

Throughout the development of China's fox image, with the increase of its hommization, the thought of era reflected from fox image is more complex. In particular, the Chinese fox image changed from auspicious into demon and charm, and then developed into a very human fox, all of which expressed people's thinking at the time. China's complexity is not only in the vertical, from the historical horizontal comparison, there are a variety of fox images exist at the same time in the same period. Song Dynasty worshiped fairy fox, even built the temple of Fox king, but at this time in fox stories the fox image was prostituted. In the Ming and Qing dynasties, the theory of fairy fox was very popular, but among many stories there were also attempt fox, crazy women, harm and other images. The complexity of Chinese fox image is precisely because of China's vast land, mixed ethnic groups, large population and other characteristics.

Ming and Qing Dynasty is the heyday of the development of novel, it means that the connotation of human nature also reached the peak in novel. "Liao Zhai Zhi Yi" not only alert people through the fox story, things the foxes did under $\mathrm{Pu}$ Songling's description are what common people will do, put aside the magic, these foxes are essentially people. $\mathrm{Pu}$ Songling failed in his official career make him closer to the bottom people, so "Strange Tales from a Chinese studio" is more secular, the expression of the stories are the most simple vision of bottom people, rather than full of rituals, nor will the story to warn people should not cling the beauty. So this formed the unique feature of "Liao Zhai Zhi $\mathrm{Yi}^{\prime}$ which is different from the mainstream fox image.

Compared with Japan, before the "Ling Gui Zhi" introduced to Japan, whether it is Inari or the fox wife, fox in Japan often exists as the image of "good". However, during the Nara period by the influence of Chinese fox culture, the Japanese people began to read a lot of Tang and Song mythical novels, the Japanese fox culture began the form which fox turn into beauty and seduce man, and gradually appeared this "evil "expression which similar to Chinese fox demon. Such as the emergence of Tomamo-no-mae, in "Shanjia Miji Chao" of "Fu Shang Lue Ji" the lust man was seduced and cheated by the fox demon and so on. Although after Nara period the image of the fox wife and Inari were still circulated, and it was given human nature during the circulation, but the proportion of this kind of "good" image began to decrease in Japanese fox culture. It can be said that the reason why Japan is contrary to the mainstream is largely influenced by the Chinese fox culture.

\section{CONCLUSION}

With the hommization of fox image, the fox image was increasingly prominent. In many Chinese and Japanese literature and folk tales, we can find that China and Japan's mainstream fox image is very different. In China the fox is mainly tempt people, and the final outcome for the men to flush out or kill the fox, its inner is meant to alert people not cling to beauty. In Japan the fox mainly exists as "good" images such like fox wife and Inari, it shows the man's infatuation. However from individual cases it reflected in Tang Dynasty Chinese culture flew into Japan, which make the Japanese fox culture changed under the influence of Chinese fox culture. After Japan's Nara era literature had more fox records and began to have the existence of "evil fox" image.

Through the comparative analysis of Chinese and Japanese fox image, behind the humanized fox image it contains the different cultures of two countries. Since ancient times, China's feudal ethical thought was vividly reflected in the fox story, but in Japan is not obvious. The differences between the two country's fox images mostly come from the different view of nature of the two countries.

In addition, from the acceptance of modern people on the fox image, in modern time people make better acceptance of the fairy fox's beautiful love story and happy ending, which results in the non-uniformity between fame and the mainstream. China and Japan's fox images gradually tend to be similar, and with the on-going development of fox image, the study on fox image will continue.

\section{REFERENCES}

[1] Hegel, "Aesthetics" Volume II "Preface. Discussion of classical art", Jiangsu People's Publishing Company, 2011

[2] Feng Guochao translated Shan Hai Jing, Volume IX - Hai Wai Dong Jing, Commercial Press, 2016

[3] Guo Pu, recorded by Zhang Zongxiang, Zuben Shan Hai Jing tuzan, P. 38, Classical literature press, 1958

[4] Ji Yun, Yuewei Caotang Notes, Volume twenty-one. Luan Yang xulusan, Shanghai: Shanghai Ancient Books Publishing Company, 1982

[5] Li Fang, Taiping Guangji: Volume 450, Beijing: Zhonghua Book Company, 1961

[6] Ji Yun, Yuewei Caotang Notes. Volume 7 - Rushiwo wenyi, Shanghai: Shanghai Ancient Books Publishing Company, 1982

[7] Jing Jie, Evil legend in Japan.The 2nd :Huweiqi lingshengzi yuan, Dahe ancient books

[8] Dong Jianghong, The fox wife image in Japanese legend, literature education, 2014

[9] Chen Dun, Sun Jingyao, Xie Tianzhen, Comparative Literature (Second Edition), P. 123, Higher Education Press, 2007 